\title{
Epidemiological and Treatment Trends of Distal Radius Fractures across Multiple Age Groups
}

\author{
Ali Azad, MD ${ }^{1} \quad$ H. Paco Kang, MD ${ }^{1} \quad$ Ram K. Alluri, MD ${ }^{1}$ Venus Vakhshori, MD ${ }^{1} \quad$ Harrison F. Kay, MD ${ }^{1}$ \\ Alidad Ghiassi, MD ${ }^{1}$ \\ ${ }^{1}$ Department of Orthopaedic Surgery, Keck Medical Center at the \\ University of Southern California, Los Angeles, California \\ Address for correspondence Ali Azad, MD, Department of \\ Orthopaedic Surgery, Keck Medical Center at the University of \\ Southern California, 1520 San Pablo Street, \#2000, Los Angeles, \\ J Wrist Surg 2019;8:305-311. \\ CA 90033 (e-mail: Ali.Azad@med.usc.edu).
}

\begin{abstract}
Keywords

- distal radius

- epidemiology

- PearlDiver

- pediatric

- elderly

- age stratification

Background The purpose of this study is to assess the epidemiology, population-specific treatment trends, and complications of distal radius fractures in the United States.

Methods The PearlDiver database (Humana [2007-2014], Medicare [2005-2014]) was used to access US inpatient and outpatient data for all patients who had undergone operative and nonoperative treatment for a distal radius fracture in the United States. Epidemiologic analysis was performed followed by age-based stratification, to assess prevalence, treatment trends, and rates of complications.

Results A total of 1,124,060 distal radius treatment claims were captured. The incidence of distal radius fractures follows a bimodal distribution with distinct peaks in the pediatric and elderly population. Fractures in the pediatric population occurred predominately in males, whereas fractures in the elderly population occurred more frequently in females. The most commonly used modality of treatment was nonoperative; however, the use of internal fixation increased significantly during the study period, from 8.75 to $20.02 \%$, with a corresponding decrease in percutaneous fixation. The overall complication rate was $8.3 \%$, with mechanical symptoms most frequently reported.

Conclusions The last decade has seen a significant increase in the use of internal fixation as treatment modality for distal radius fractures. The impetus for this change is likely multifactorial and partly related to recent innovations including volar locking plates and an increasingly active elderly population. The implicated financial cost must be weighed against the productivity cost of maintaining independent living to determine the true burden to the healthcare system.
\end{abstract}

Over 640,000 radius and/or ulna fractures were reported in 2001 in the United States, accounting for approximately $1.5 \%$ of all emergency department visits. ${ }^{1,2}$ Distal radius fractures account for 25 and $18 \%$ of all fractures in the pediatric and elderly population, respectively. ${ }^{3,4}$ Surgical treatment in young adults has been advocated to decrease the morbidity associated with malunion. ${ }^{5,6}$ However, in the aging population with lower functional demands, these fractures have traditionally been treated with cast immobilization, yielding satisfactory results despite significant secondary displacement with subsequent malunion. ${ }^{7-10}$ Advocates for internal

received

January 7, 2019

accepted after revision

February 27, 2019

published online

April 16, 2019 fixation in this population argue that simple fractures in the setting of osteoporosis are inherently unstable and have shown good final results with early return to function and low complication rate following internal fixation. ${ }^{11}$

The distal radius practice guidelines approved by the American Academy of Orthopaedic Surgeons in 2009 recommended with moderate-strength, surgical fixation rather than cast fixation for fractures with post-reduction radial shortening $>3 \mathrm{~mm}$, dorsal tilt $>10$ degrees, or intraarticular displacement or step-off $>2 \mathrm{~mm} .{ }^{12}$ These guidelines were followed up with Appropriate Use Criteria (AUC)
Copyright $\odot 2019$ by Thieme Medical Publishers, Inc., 333 Seventh Avenue, New York, NY 10001, USA. Tel: +1(212) 584-4662.
DOI https://doi.org/ 10.1055/s-0039-1685205. ISSN 2163-3916. 
based on fracture type, mechanism of injury, activity level of patient, patient health, and other injuries. ${ }^{13}$ Unfortunately, the initial guidelines and AUC scoring system do not provide clear indications with most recommendations graded as inconclusive. None of the 29 recommendations were graded as strong. Other indications cited in the literature include unstable fractures as defined by Lafontaine et al and Mackenney et al, open fractures, polytrauma patients, and concomitant carpal fractures. ${ }^{14-16}$ Although fixation-specific recommendations remain vague, the past several decades have seen an evolution in fixation options with dorsal plating in the 1990s, followed by volar plating in 2000, and the subsequent advent of fragment-specific fixation in 2014. ${ }^{14,17,18}$ The influence of these innovations on distal radius fracture treatment trends remains unclear.

The purpose of this study is to (1) characterize the incidence of distal radius fractures in the United States based on age and gender, (2) to examine population-specific trends in the treatment of distal radius fractures, and (3) to evaluate complications associated with each treatment modality.

\section{Materials and Methods}

Deidentified patient insurer data from the Medicare Standard Analytic File was queried using PearlDiver software (PearlDiver Inc., Colorado Springs, CO). The database stores longitudinal patient data as gathered by billing information and includes diagnoses, procedures, and patient and provider characteristics, among other information. Given Medicare's focus on the elderly, this data was supplemented with deidentified patient data from Humana, a large national private insurer covering 21 million patients, to provide a full spectrum of ages. The Humana dataset was similarly analyzed using PearlDiver.

A retrospective review was conducted on the entire database, from 2007 through 2014 for Humana, and 2005 through 2014 for Medicare. Patients with distal radius fractures were identified with the relevant International Classification of Diseases, 9th revision (ICD-9) codes. Of this cohort, we then identified patients treated nonoperatively and those who subsequently underwent percutaneous fixation or internal fixation within 14 days by their relevant Current Procedural Terminology (CPT) codes. This timeframe was chosen as to not introduce confounding by patients requiring corrective surgery for malunion or nonunion. To examine treatment trends in different age groups, the patients in the database were stratified into four groups (0-19, 20-39, 40-64, and 65 years of age). For patient privacy protection purposes, groups with 10 patients or fewer are not reported by the database and as such were not represented in the graphical analysis. Complications were identified using ICD-9 codes and analyzed based on age and treatment modality.

Statistical analysis was performed using Microsoft Excel (Microsoft Corp, Redmond WA). Trend lines were calculated using the least squares method, with the significance being reported for the calculated $p$-value. Comparisons of complication rates were performed using a chi-squared test.

\section{Results}

Over the 10-year period from 2005 to 2014, the PearlDiver research program captured over 1 million $(1,124,060)$ distal radius fracture treatment claims. The average annual incidence of distal radius fracture treatment claims was 112,406 claims (range, 103,273-116,793 claims). There is a bimodal distribution in which there is a peak at age 10 to 14 , followed by a peak during the seventh and eight decades of life (-Fig. 1). Males had higher incidence of fracture in the 0 to 19 age group (60.2\%), while females had a higher incidence of fracture in the 40 to 64 (71.1\%), and $\geq 65$ (85.4\%) age groups (-Fig. 2 ).

The most frequently used modality of treatment was closed reduction and casting treatment. In 2005, approximately $86 \%$ of distal radius fracture treatment claims were for closed treatment. This steadily declined over the 10 -year period to $77.5 \%$. The proportion of patients managed with closed reduction and percutaneous fixation also declined, from $5.43 \%$ in 2005 to $2.54 \%$ in $2014\left(r^{2}=0.97, p<0.0001\right.$ ).

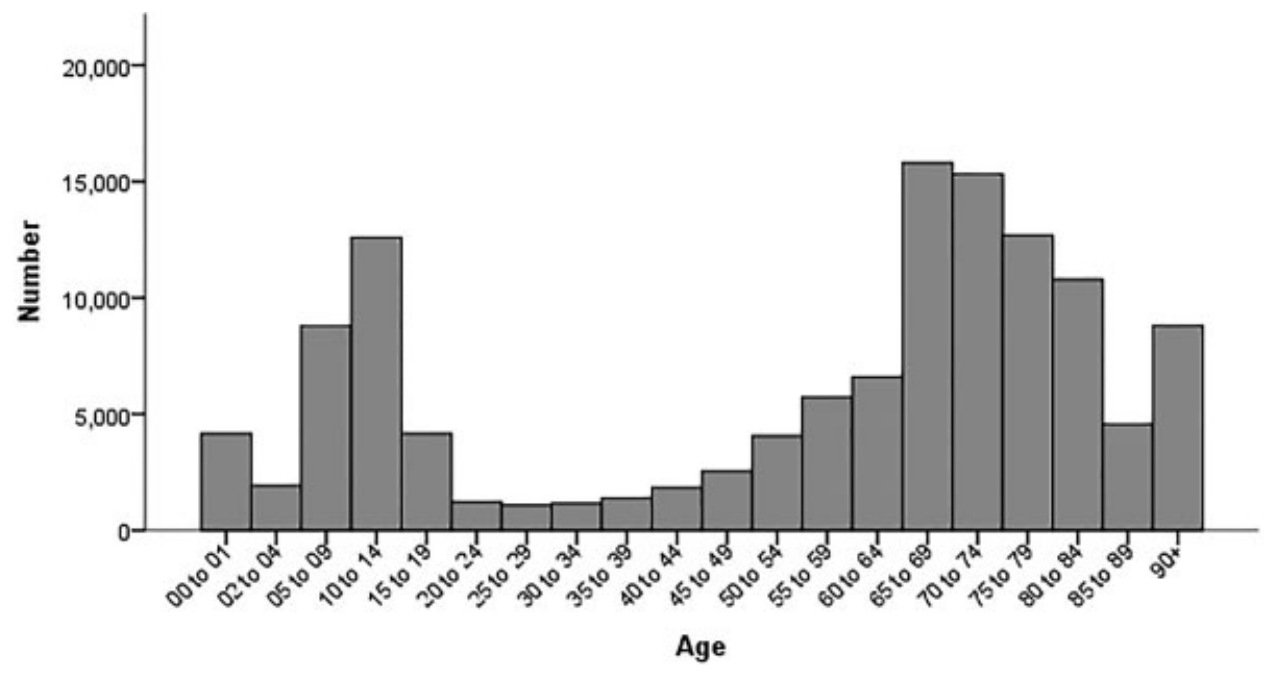

Fig. 1 Distal radius fracture distribution by age group. 


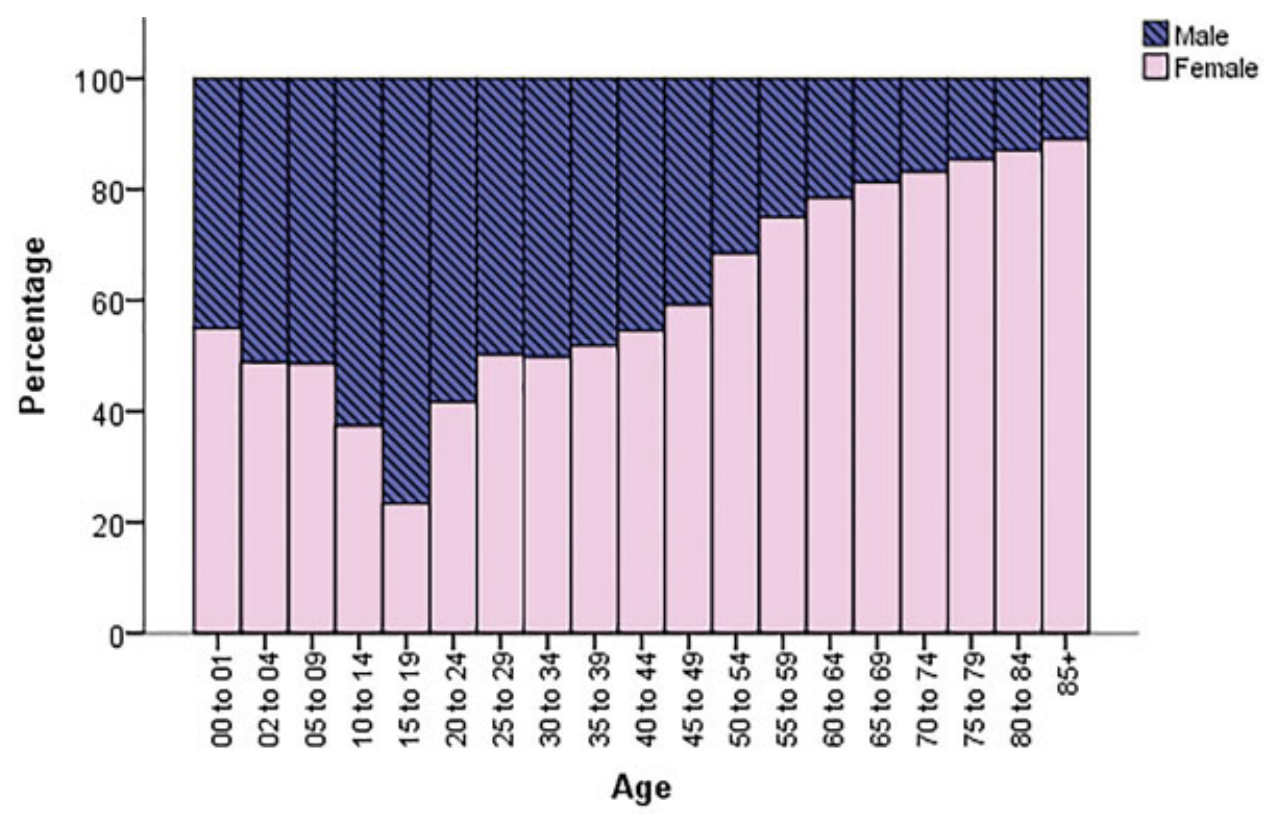

Fig. 2 Gender distribution in distal radius fractures by age group.

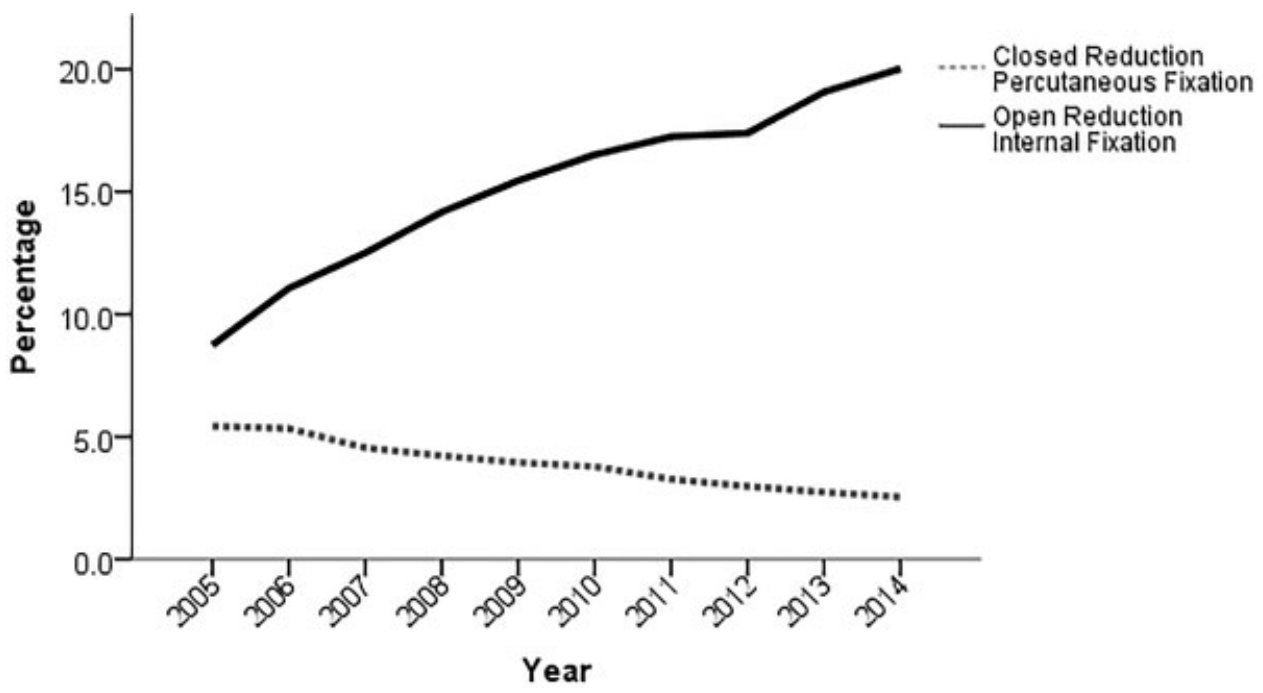

Fig. 3 Annual trend in the use of open reduction internal fixation (ORIF) and closed reduction percutaneous fixation (percentage). There has been a linear increase in ORIF in the timeframe of the study $\left(r^{2}=0.98, p<0.0001\right)$ with a concomitant linear decrease in percutaneous pinning $\left(r^{2}=0.97, p<0.0001\right)$.

The decreasing trend in the use of closed reduction and percutaneous fixation corresponded to an increasing trend in the use of internal fixation. Its use as the modality of treatment increased from $8.75 \%$ in 2005 to $20.02 \%$ in 2014 $\left(r^{2}=0.98, p<0.0001\right)$ (-Fig. 3).

Population-specific analysis based on age group revealed the most frequent modality of treatment used overall was closed reduction for all age groups (-Table 1). This was followed in descending order by internal fixation and percutaneous pinning for all age groups except those 0 to 19 years of age, for which percutaneous pinning was the second most frequently used modality. An analysis of these groups over time revealed a decreasing trend in the use of percutaneous pinning in each group except those 0 to 19 years of age, which maintained a constant rate of approximately $2 \%$ (-Fig. 4A). The rate of internal fixation for this group also remained constant (1.1-1.3\%) over the study period, whereas the use of this modality increased for those aged between 20 and 39 (19.8-24.6\%), aged between 40 and 64 (18.5-29.7\%), and aged $\geq 65(9.9-23.4 \%)$ (-Fig. 4B). The largest percentage increase in the use of internal fixation over the duration of the study was seen in those $>65$ years of age.

The overall complication rate was $8.3 \%$ and includes malunion, nonunion, infection, tendon rupture, contractures, mechanical symptoms, and complex regional pain syndrome (-Table 2). The complication rate associated with nonoperative and operative modalities was 5.4 and $9.4 \%$, respectively. Mechanical symptoms were the most commonly reported complication overall (2.06\%) as well as for the operative (2.82\%) and nonoperative (1.83\%) subgroups. Compared to the nonoperative group, the group that received operative intervention had a statistically significant higher rate of 
Table 1 Distal radius fracture treatment modality by age group

\begin{tabular}{|l|l|l|l|l|}
\hline & $\begin{array}{l}\text { All distal radius } \\
\text { fractures }\end{array}$ & $\begin{array}{l}\text { Percutaneous } \\
\text { fixation }\end{array}$ & $\begin{array}{l}\text { Open reduction } \\
\text { internal fixation }\end{array}$ & Nonoperative \\
\hline Pediatric (0-19) & 27,564 & $730(2.65 \%)$ & $398(1.44 \%)$ & $26,378(95.7 \%)$ \\
\hline Young (20-39) & 4,689 & $150(3.2 \%)$ & $1,145(24.42 \%)$ & $3,372(71.91 \%)$ \\
\hline Middle aged (40-64) & 20,048 & $840(4.19 \%)$ & $6,366(31.75 \%)$ & $12,747(63.58 \%)$ \\
\hline Elderly (65 and above) & 939,448 & $37,337(3.97 \%)$ & $168,978(17.99 \%)$ & $731,746(77.89 \%)$ \\
\hline
\end{tabular}
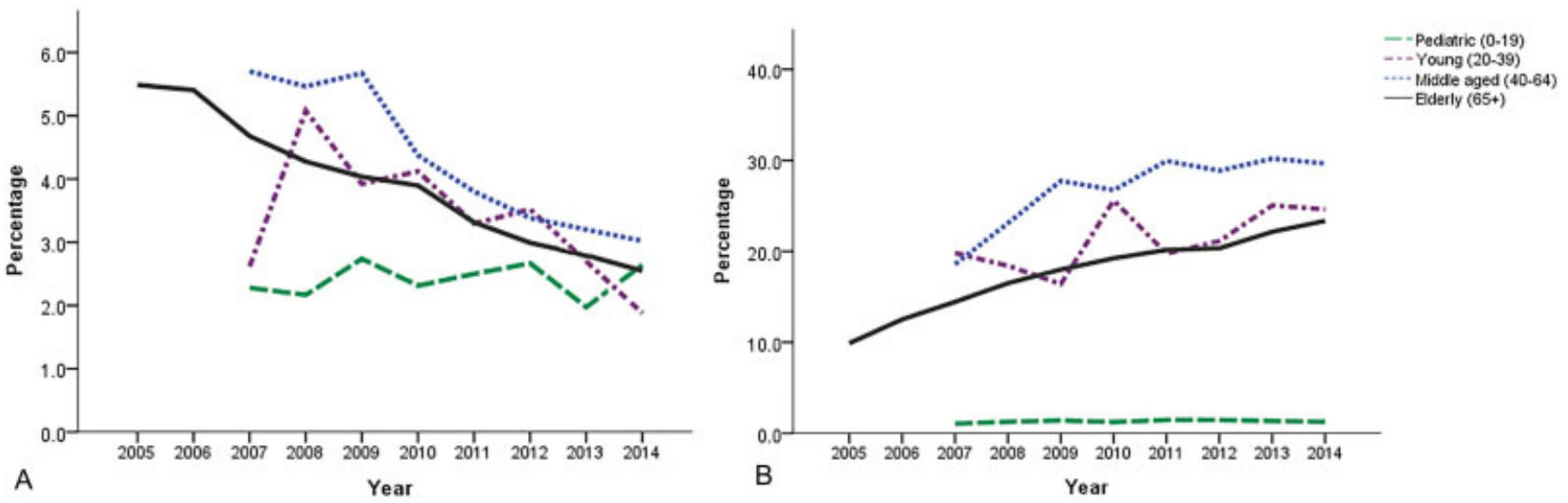

Fig. 4 Annual trend in closed reduction percutaneous fixation (A) and open reduction internal fixation (B) by age group.

Table 2 Complications after distal radius treatment by treatment group. The operative group had a higher rate of every complication examined compared to the nonoperative treatment group

\begin{tabular}{|l|l|l|l|l|}
\hline & All & Operative & Nonoperative & $p$-Value \\
\hline Malunion & $13,281(1.18 \%)$ & $1,972(0.92 \%)$ & $10,489(1.16 \%)$ & $<0.0001$ \\
\hline Nonunion & $14,744(1.31 \%)$ & $3,017(1.4 \%)$ & $11,307(1.25 \%)$ & $<0.0001$ \\
\hline Infection & & $5,008(2.33 \%)$ & N/A & N/A \\
\hline Tendon rupture & $2,581(0.23 \%)$ & $1,038(0.48 \%)$ & $1,487(0.16 \%)$ & $<0.0001$ \\
\hline Contractures & $9,502(0.85 \%)$ & $2,075(0.96 \%)$ & $6,931(0.76 \%)$ & $<0.0001$ \\
\hline Mechanical symptoms & $23,068(2.06 \%)$ & $6,063(2.82 \%)$ & $16,637(1.83 \%)$ & $<0.0001$ \\
\hline CRPS & $\begin{array}{l}3,399 \\
(0.30 \%)\end{array}$ & $\begin{array}{l}2,374(0.26 \%) \\
\end{array}$ & $<0.0001$ \\
\hline
\end{tabular}

Abbreviation: CRPS, complex regional pain syndrome.

occurrence of every complication, except malunion. The rate of occurrence of specific complications in patients treated with internal fixation in descending order was mechanical symptoms (2.73\%), superficial and deep infection $(2.14 \%)$, nonunion (1.33\%), contractures $(0.96 \%)$, malunion $(0.78 \%)$, and tendon rupture (0.55\%). Although tendon rupture was one of the least commonly reported complication in patients treated with internal fixation, it was reported with three times greater frequency than in patients treated nonoperatively.

\section{Discussion}

The current data presents a 10 -year review of distal radius fractures revealing the current epidemiology and trends in treatment as well as associated complications. The present study reveals a bimodal distribution with peaks in the pediatric population (10-14 years) and those $\geq 65$ years of age. An analysis of occurrence based on gender revealed a greater proportion of distal radius fractures in the pediatric population occurred in males. These results confirm findings by Bailey et al, which revealed a peak rate of occurrence for girls between the ages 11.5 and 12.5 years, and for boys between 13.5 and 14.5 years. ${ }^{19}$ Several studies have attributed the peak in incidence seen in the pediatric population to a combination of increased fragility of bones during peak growth velocity and increased physical activity. ${ }^{19-22}$ Several other authors have demonstrated similar findings based on gender. ${ }^{22-24}$ Landin studied fracture patterns in children and noted the accumulated risk of fracture was $27 \%$ in girls and $42 \%$ in boys. ${ }^{23} \mathrm{~A}$ similar trend is seen in a study by Ryan et al, 
which demonstrated a $64 \%$ of pediatric forearm fractures occurred in boys. ${ }^{24}$

In contrast to the peak seen in the pediatric population, a majority of distal radius fractures in the elderly population occurred in females. Baron et al found a significant gender difference in the occurrence of fractures of the distal forearm. $^{3}$ They noted a female:male rate ratio of 4.88 , in contrast to a ratio of 3 in other upper extremity fractures. Other studies have noted similar findings with up to five times greater fracture incidence in women than in men. ${ }^{19,25}$ The major attributable risk factor to these findings is osteoporosis. In 2002, the National Osteoporosis Foundation estimated that there are 9.1 million women and 2.8 million men with osteoporosis. ${ }^{26}$ Kanterewicz et al showed that wrist fractures were more prevalent in postmenopausal women with osteoporosis compared to those without. ${ }^{27}$ Several other studies have also linked the relationship between decrease bone mineral density as a predictor for distal radius fractures as well the severity of the fractures. ${ }^{28,29}$

Recent studies have focused primarily on treatment trends in the elderly population without age stratification. $^{30,31}$ The present study provides an overall look at treatment trends in the United States with additional analysis to include age stratification and treatment-specific complication rates. The increasing trend in the use of internal fixation with corresponding decreases in the use of percutaneous and closed reduction are findings supported by multiple studies. ${ }^{30,31}$ Chung et al evaluated Medicare data from 1996 to 2005 showing fivefold increase in the rate of internal fixation of distal radius fractures in the elderly. ${ }^{30}$ In a study of submitted case lists to the American Board of Orthopaedic Surgery from 1999 to 2007, Koval et al found a significant increase in the proportion of distal radius fractures stabilized with internal fixation. ${ }^{31}$ The present study provides further analysis with age stratification. The greatest change in overall practice patterns over the study period was seen in the group $\geq 65$ years of age, followed by those between 40 and 64 years of age, with an increased use of internal fixation seen in both. The rate of percutaneous fixation and internal fixation remained constant in the pediatric population.

In a multicenter prospective randomized controlled trial comparing plate fixation to percutaneous and external fixation, Leung et al reported better functional scores with plate fixation. ${ }^{32}$ Other studies have looked at volar plate fixation specifically and found satisfactory outcomes in support of the internal fixation as a treatment modality. ${ }^{11,33,34}$ Inconclusive clinical practice guidelines in addition to advances to internal fixation including lower profile designs, proximal/distal fit plates, polyaxial capabilities, periarticular hook plates/extensions, and fragment-specific fixation could be considered to play a role in the continued increasing trend of internal fixation. ${ }^{14,17}$ The change toward more fracture fixation seen in the elderly population could in part be attributed to the increased risk of loss of reduction and malunion due to the inherent instability associated with osteopenia and osteoporosis. ${ }^{15,16,28}$ Several authors have postulated that the stability offered by internal fixation allows for an earlier ability to perform activities of daily living and thereby preserving independence, while Koval et al eluded to an "intrinsic attraction newer technology" and pressures to offer new techniques. ${ }^{30,31}$ Egol et al performed a retrospective study comparing closed reduction and casting to operative treatment in patients over the age of 65 and found superior radiographic outcomes with operative intervention; however, there was no difference in functional status between the two groups at final follow-up. ${ }^{35}$ A study by Arora et al comparing closed reduction and casting to internal fixation with volar locking plate found similar results with regard to radiographic and functional outcomes. ${ }^{36}$ Shauver et al studied the financial impact of the increasing trend for operative treatment of distal radius fractures in the elderly population. ${ }^{37}$ They found that in 2007, Medicare made $\$ 170$ million in distal radius fracture-related payments and estimated the future cost in the elderly population could reach $\$ 240$. The authors concluded that the rapid increase in treatment cost due to the more frequent use of internal fixation will result in a substantial increase in healthcare costs requiring closed evaluation and allocation of resources. ${ }^{37}$

The complication rate associated with distal radius fractures treated nonoperatively and operatively was 5.4 and $9.4 \%$, respectively, which is consistent with the current literature. $^{38,39}$ The most frequently reported complication independent of modality of treatment was mechanical symptoms. Due to the limited patient-level data in the database, further characterizing this complication was not possible. Current literature uses the term "mechanical symptoms" to include distal radioulnar joint dysfunction/arthritis, ulnar impaction syndrome, tendonitis, among other causes of wrist pain. Malunion was the only complication that occurred more frequently in patients managed nonoperatively. This is consistent with multiple comparative studies, although their findings did not correlate to worse functional status. ${ }^{35,36}$

Our study has several limitations. The analysis is dependent on accurate documentation of ICD-9 and CPT codes. The most commonly used code for internal fixation of distal radius fractures captures volar plates, dorsal plates, fragment-specific fixation, etc. Therefore, conclusions cannot be made regarding approach, construct design, or specific implant. A similar limitation is seen with percutaneous fixation. A single CPT code is used to capture Kirschner-wire fixation, standard external fixation, or even if an open reduction was performed. Some authors use a two-step approach by first determining capturing all distal radius fractures with an ICD-9 code followed by the CPT code for external fixation; however, this methodology can overestimate the use of external fixation by including patients with distal radius fractures that have had external fixation for injuries on other extremities. Lastly, there is a paucity of detailed clinical data that is inherent to database studies due to an inability to perform a chart review. Lastly, in the current study, we discussed complication trends including mechanical symptoms; however, we are unable to elaborate on the specific nature or temporality of the symptom.

In conclusion, there has been a significant change in the treatment trend of distal radius fractures in the United States 
over the 10-year study period. The impetus for the increasing use of internal fixation is likely multifactorial and remains conjecture at this point in time. Possible causes include a lack of clear clinical practice guidelines, innovations to implant design, an increasingly active aging population, patient expectations including a desire for expedited recovery, and the practice of defensive medicine due to the stigma of functional malunion. Additionally, the implicated financial cost associated with the increased use of internal fixation must be weighed against the productivity cost of maintaining independent living to determine the true burden to the healthcare system.

\section{Funding \\ None. \\ Conflict of Interest \\ None declared.}

\section{References}

1 Chung KC, Spilson SV. The frequency and epidemiology of hand and forearm fractures in the United States. J Hand Surg Am 2001; 26(05):908-915

2 Larsen CF, Lauritsen J. Epidemiology of acute wrist trauma. Int J Epidemiol 1993;22(05):911-916

3 Baron JA, Karagas M, Barrett J, et al. Basic epidemiology of fractures of the upper and lower limb among Americans over 65 years of age. Epidemiology 1996;7(06):612-618

4 Rennie L, Court-Brown CM, MokJYQ, Beattie TF. The epidemiology of fractures in children. Injury 2007;38(08):913-922

5 Knirk JL, Jupiter JB. Intra-articular fractures of the distal end of the radius in young adults. J Bone Joint Surg Am 1986;68(05): 647-659

6 Kopylov P, Johnell O, Redlund-Johnell I, Bengner U. Fractures of the distal end of the radius in young adults: a 30-year follow-up. J Hand Surg [Br] 1993;18(01):45-49

7 Anzarut A, Johnson JA, Rowe BH, Lambert RGW, Blitz S, Majumdar SR. Radiologic and patient-reported functional outcomes in an elderly cohort with conservatively treated distal radius fractures. J Hand Surg Am 2004;29(06):1121-1127

8 Grewal R, MacDermid JC. The risk of adverse outcomes in extraarticular distal radius fractures is increased with malalignment in patients of all ages but mitigated in older patients. J Hand Surg Am 2007;32(07):962-970

9 Hegeman JH, Oskam J, Vierhout PA, Ten Duis HJ. External fixation for unstable intra-articular distal radial fractures in women older than 55 years. Acceptable functional end results in the majority of the patients despite significant secondary displacement. Injury 2005;36(02):339-344

10 Young BT, Rayan GM. Outcome following nonoperative treatment of displaced distal radius fractures in low-demand patients older than 60 years. J Hand Surg Am 2000;25(01):19-28

11 Orbay JL, Fernandez DL. Volar fixed-angle plate fixation for unstable distal radius fractures in the elderly patient. J Hand Surg Am 2004;29(01):96-102

12 Lichtman DM, Bindra RR, Boyer MI, et al. Treatment of distal radius fractures. J Am Acad Orthop Surg 2010;18(03): 180-189

13 Watters WC, Sanders JO, Murray J, Patel N; Members of the Writing, Review, and Voting Panels of the AUC on the Treatment of Distal Radius Fractures. The American Academy of Orthopaedic Surgeons Appropriate Use Criteria on the treatment of distal radius fractures. J Bone Joint Surg Am 2014;96(02):160-161
14 Alluri RK, Hill JR, Ghiassi A. Distal radius fractures: approaches, indications, and techniques. J Hand Surg Am 2016;41(08): 845-854

15 Lafontaine M, Hardy D, Delince P. Stability assessment of distal radius fractures. Injury 1989;20(04):208-210

16 Mackenney PJ, McQueen MM, Elton R. Prediction of instability in distal radial fractures. J Bone Joint Surg Am 2006;88(09): 1944-1951

17 Bakker AJ, Shin AY. Fragment-specific volar hook plate for volar marginal rim fractures. Tech Hand Up Extrem Surg 2014;18(01): $56-60$

18 Orbay JL. The treatment of unstable distal radius fractures with volar fixation. Hand Surg 2000;5(02):103-112

19 Bailey DA, Wedge JH, McCulloch RG, Martin AD, Bernhardson SC. Epidemiology of fractures of the distal end of the radius in children as associated with growth. J Bone Joint Surg Am 1989; 71(08):1225-1231

20 Caspersen CJ, Pereira MA, Curran KM. Changes in physical activity patterns in the United States, by sex and cross-sectional age. Med Sci Sports Exerc 2000;32(09):1601-1609

21 Krabbe S, Christiansen C, Rødbro P, Transbøl I. Effect of puberty on rates of bone growth and mineralisation: with observations in male delayed puberty. Arch Dis Child 1979;54 (12):950-953

22 Nellans KW, Kowalski E, Chung KC. The epidemiology of distal radius fractures. Hand Clin 2012;28(02):113-125

23 Landin LA. Fracture patterns in children. Analysis of 8,682 fractures with special reference to incidence, etiology and secular changes in a Swedish urban population 1950-1979. Acta Orthop Scand Suppl 1983;202:1-109

24 Ryan LM, Teach SJ, Searcy K, et al. Epidemiology of pediatric forearm fractures in Washington, DC. J Trauma 2010;69(4, Suppl): S200-S205

25 Brogren E, Petranek M, Atroshi I. Incidence and characteristics of distal radius fractures in a southern Swedish region. BMC Musculoskelet Disord 2007;8:48

26 America's Bone Health: The State of Osteoporosis and Low Bone Mass in Our Nation. Washington, DC: National Osteoporosis Foundation; 2002

27 Kanterewicz E, Yañez A, Pérez-Pons A, Codony I, Del Rio L, DíezPérez A. Association between Colles' fracture and low bone mass: age-based differences in postmenopausal women. Osteoporos Int 2002;13(10):824-828

28 Clayton RAE, Gaston MS, Ralston SH, Court-Brown CM, McQueen MM. Association between decreased bone mineral density and severity of distal radial fractures. J Bone Joint Surg Am 2009;91 (03):613-619

29 Oyen J, Brudvik C, Gjesdal CG, Tell GS, Lie SA, Hove LM. Osteoporosis as a risk factor for distal radial fractures: a case-control study. J Bone Joint Surg Am 2011;93(04):348-356

30 Chung KC, Shauver MJ, Birkmeyer JD. Trends in the United States in the treatment of distal radial fractures in the elderly. J Bone Joint Surg Am 2009;91(08):1868-1873

31 Koval KJ, Harrast JJ, Anglen JO, Weinstein JN. Fractures of the distal part of the radius. The evolution of practice over time. Where's the evidence? J Bone Joint Surg Am 2008;90(09): 1855-1861

32 Leung F, Tu Y-K, Chew WYC, Chow S-P. Comparison of external and percutaneous pin fixation with plate fixation for intra-articular distal radial fractures. A randomized study. J Bone Joint Surg Am 2008;90(01):16-22

33 Beharrie AW, Beredjiklian PK, Bozentka DJ. Functional outcomes after open reduction and internal fixation for treatment of displaced distal radius fractures in patients over 60 years of age. J Orthop Trauma 2004;18(10):680-686

34 Jupiter JB, Ring D, Weitzel PP. Surgical treatment of redisplaced fractures of the distal radius in patients older than 60 years. J Hand Surg Am 2002;27(04):714-723 
35 Egol KA, Walsh M, Romo-Cardoso S, Dorsky S, Paksima N. Distal radial fractures in the elderly: operative compared with nonoperative treatment. J Bone Joint Surg Am 2010;92(09):1851-1857

36 Arora R, Gabl M, Gschwentner M, Deml C, Krappinger D, Lutz M. A comparative study of clinical and radiologic outcomes of unstable Colles type distal radius fractures in patients older than 70 years: nonoperative treatment versus volar locking plating. J Orthop Trauma 2009;23(04):237-242
37 Shauver MJ, Yin H, Banerjee M, Chung KC. Current and future national costs to Medicare for the treatment of distal radius fracture in the elderly. J Hand Surg Am 2011;36(08):1282-1287

38 Mathews AL, Chung KC. Management of complications of distal radius fractures. Hand Clin 2015;31(02):205-215

39 McKay SD, MacDermid JC, Roth JH, Richards RS. Assessment of complications of distal radius fractures and development of a complication checklist. J Hand Surg Am 2001;26(05):916-922 